CP, 2018, Vol.7 - No15, pp. 9/25 ISSN 2014-6752. Girona (Catalunya). Universitat de Girona. MATOS E NOBRE, HELOIZA; COSTA OLIVEIRA, MARIA JOSÉ DA: Uma perspectiva ampliada para as Relações Públicas na articulação entre o interesse privado e público. Recibido: 9/05/2018 - Aceptado: 24/09/2018

\title{
Uma perspectiva ampliada para as Relações Públicas na articulação entre o interesse privaḑo e público
}

\section{Una perspectiva ampliada para las relaciones públicas en la articulación entre el interés privado y público}

\section{An expanded perspective for Public Relations in the articulation between the private and public interests}

\begin{abstract}
Autoras:
Heloiza MATOS E NOBRE

Docente Permanente e Pesquisadora Sênior do Programa de Pós-Graduação em Comunicação da Escola de Comunicações e Artes da Universidade de São Paulo; Coordenadora do Compol Grupo de Pesquisa em Comunicação Pública e Política. heloizamatos@gmail.com

Maria José da COSTA OLIVEIRA

Pós-doutora pelo PPGCom/Escola de Comunicações e Artes da Universidade de São Paulo; membro e vice-coordenadora do Compol - Grupo de Pesquisa em Comunicação Pública e Política. zezecoliveira@gmail.com
\end{abstract}

\section{Resumo}

Este artigo analisa, por uma perspectiva crítica, as Relações Públicas diante da diluição das fronteiras entre a esfera organizacional e as esferas públicas, uma vez que esta atividade mantém sua interface direta com a democracia, quando contribui para construir relacionamentos estratégicos que levem em conta não apenas os recursos comunicativos, mas também as transformações nos padrões de engajamento dos cidadãos. Por isso, as estratégias e políticas de Relações Públicas podem ser dimensionadas de forma ampliada quando extrapolam os interesses organizacionais, principalmente se considerarmos que, no contexto democrático, o foco é o cidadão, que deixou de ser mero receptor para tornar-se sujeito do processo. Assim, surgem demandas por relações que possibilitem o diálogo, a participação e a deliberação para a tomada de decisões em ambientes privados e públicos. Todavia, as práticas de Relações Públicas são alvos de críticas por ainda priorizarem o interesse empresarial ou político, desencadeando a discussão se po-

\section{Abstract}

This article analyzes the public relations from a critical perspective, amid the blurring of the boundaries between the organizational and public spheres, since such activity maintains its interface with democracy, when it contributes to building strategic relationships that take into account the communicative resources, but also the changes in the standards of citizen engagement. Therefore, public relations strategies and policies can be broadened when they extrapolate organizational interests, especially considering that (in a democratic context) the focus is on the citizen, who is no longer a simple receiver - but rather a subject in the process. Thus, demands arise for relationships that enable dialogue, participation, and deliberation toward decision-making in private and public environments. However, public relations practices are subject to criticism, because they seem to still prioritize business or political interests, triggering discussion as to whether they could coexist with democracy. Here 
deriam, de fato, coexistir com a democracia. the exploratory-descriptive study is based on Assim, este estudo exploratório-descritivo, tem a bibliographical research, which is guided by por base pesquisa bibliográfica que se fundamenta nos conceitos de entendimento, resolução de conflitos e discurso, explorados a partir da Teoria da Ação Comunicativa de Jürgen Habermas (1984, 1987). A abordagem sobre esfera pública e democracia deliberativa também se alicerça em Habermas e autores que o tem como a principal referência. Já a abordagem crítica sobre Relações Públicas, encontra referência nos trabalhos de Gonçalves (2007) e Peruzzo (1986, 2004, 2009). O conceito de capital social, aqui tratado por evidenciar os vínculos presentes nos grupos que podem estar ligados direta ou indiretamente às organizações, se respalda em especial na obra de Putnam (1997) e Matos (2007, 2009).

Do entrelaçamento desses conceitos, resulta a análise sobre o necessário compromisso das Relações Públicas com o interesse público, com os valores democráticos e com a construção da cidadania. the concepts of understanding, conflict resolution, and discourse; all from the Theory of Communicative Action by Jürgen Habermas (1984, 1987). The approaches for the public sphere and deliberative democracy were also based on Habermas, and also on authors who had him as the main reference. On the other hand, the critical approach to public relations was found in the works of Gonçalves (2007) and Peruzzo (1986, 2004, 2009). The concept of social capital, here treated as evidencing the bonds between the groups that may be (in)directly linked to organizations, was based in Putnam (1997) and Matos $(2007,2009)$. From the intertwining of these concepts results the necessary commitment of public relations with the public interest, democratic values, and the construction of citizenship.

\section{Resumen}

Este artículo analiza las relaciones públicas desde una perspectiva crítica, en medio de la oscuridad de los límites entre las esferas organizativa y pública, ya que dicha actividad mantiene su enlace con la democracia, cuando contribuye a construir relaciones estratégicas basadas en los recursos comunicativos, pero también basadas en los cambios de los estándares de la participación ciudadana. Por lo tanto, las estrategias y políticas de relaciones públicas pueden ampliarse para extrapolar los intereses organizativos, especialmente en un contexto democrático donde la atención se centra en el ciudadano, que ya no es un simple receptor - sino un sujeto en el proceso. Por lo tanto, surgen demandas para las relaciones que permitan el diálogo, la participación y la deliberación hacia la toma de decisiones en entornos públicos y privados. Sin embargo, las prácticas de relaciones públicas están sujetas a críticas, ya que parecen dar prioridad a los intereses empresariales o políticos, lo que desencadena la discusión sobre si podrían coexistir con la democracia. Aquí el estudio exploratorio-descriptivo se basa en una investigación bibliográfica, que se guía por los conceptos de comprensión, resolución de conflictos y discurso; todo desde la Teoría de la Acción Comunicativa de Jürgen Habermas (1984, 1987). Los enfoques para la esfera pública y la democracia deliberativa también se basaron en Habermas, y en los autores que lo tenían como referencia principal.

Por otro lado, el enfoque crítico de las relaciones públicas se encontró en los trabajos de Gonçalves (2007) y Peruzzo (1986, 2004, 2009). El concepto de capital social, tratado como evidencia de los vínculos entre los grupos que pueden estar (in)directamente vinculados a las 
organizaciones, se basó en Putnam (1997) y Matos (2007, 2009). Del entrelazamiento de estos conceptos resulta el compromiso necesario de las relaciones públicas con el interés público, los valores democráticos y la construcción de la ciudadanía.

\section{Palavras-chave:}

Cidadania; Democracia; Esfera Pública; Relações Públicas; Capital Social.

Keywords:

Citizenship; Democracy; Public Sphere; Public Relations; Social Capital.

Palabras clave:

La ciudadanía; Democracia; Esfera Pública; Relaciones públicas; Capital social.

\section{Introdução}

O contexto atual tem ampliado a perspectiva de atuação das Relações Públicas para além das organizações, em decorrência das transformações da comunicação e do surgimento de recursos tecnológicos que levam à diluição das fronteiras entre o público e o privado. Como consequência desse movimento, intensifica-se também a necessidade de políticas e estratégias de relacionamento, que levem em conta as demandas das esferas públicas. Nesse sentido, a presente análise fundamenta-se na teoria crítica para refletir sobre uma alternativa para a práxis das Relações Públicas, com potencial de sugerir caminhos para a ação social e política.

Conforme sintetizado na matriz de tradições teóricas proposta por Craig e Muller (2007), a teoria crítica permite compreender as práticas de comunicação como uma reflexão discursiva. A presente pesquisa considera que a prática das Relações Públicas está inserida numa ideologia presente, mas também reconhece que o discurso dominante, por sua vez, articula-se dialeticamente com ações de conscientização e com espaços de emancipação que resistem à opressão das relações de poder nos contextos organizacionais.

Aqui se utiliza a pesquisa bibliográfica, coerente com estudos exploratórios e descritivos, já que o objeto de estudo proposto é pouco estudado, tornando difícil a formulação de hipóteses precisas e operacionalizáveis. Além disso, a pesquisa bibliográfica possibilita um amplo alcance de informações, além de permitir a utilização de dados dispersos em inúmeras publicações, auxiliando também na construção, ou na melhor definição do quadro conceitual que envolve o objeto de estudo proposto (GIL, 1994).

Neste artigo, iniciamos com a constatação de que diversos autores registram em suas obras uma crítica às Relações Públicas, por sua contribuição restrita ao sucesso empresarial, ou por seu uso como apenas uma técnica de informação - o que reflete uma visão funcionalista e limitante da atividade, com foco estratégico nas organizações. É recorrente a tendência de estudiosos que as associam a estratégias de manipulação da opinião pública e de jogos do poder. Gonçalves (2007: 2), por exemplo, chega a questionar o verdadeiro papel da profissão de Relações Públicas na sociedade e analisa a importância das associações profissionais para desenvolverem, promoverem e cobrarem a adoção de códigos éticos e de conduta, apelando para práticas que enfatizem a verdade, o diálogo e o interesse público como valores centrais da profissão. 
Para Rüdiger (2011:42), as críticas às Relações Públicas são antigas, numerosas e se originam de vários campos da sociedade, pois, há muito tempo a atividade tem provocado polêmica e contestação, a partir dos diversos setores do público, até os poderes políticos organizados, passando pela própria esfera dos negócios.

As posições críticas a respeito da prática das Relações Públicas realizadas, tanto no âmbito empresarial, como político (Gonçalves, 2007:4), enfatizam que o consumidor, ou o cidadão em geral, é alvo de estratégias que o conduzem a aceitar uma versão parcial e manipulada da realidade. Uma perspectiva que, segundo Gonçalves, pode mesmo conduzir à questão sobre se, em última instância, Relações Públicas e a democracia podem coexistir (idem:8).

Peruzzo, desde o início da década de 80, já evidenciava sua posição crítica sobre as Relações Públicas, quando analisou o papel da área no modo de produção capitalista (1986), evidenciando que as Relações Públicas têm, por finalidade, fazer com que o interesse privado adquira uma roupagem de interesse público.

Em sua obra, Peruzzo procurou compreender o real sentido das Relações Públicas quando utilizadas por empresas, organizações civis e por governos na sociedade capitalista.

A autora (2009:158), avalia que as Relações Públicas se juntam a outras estratégias políticoorganizacionais com a finalidade de harmonizar as relações capital-trabalho, além de tentar obter o consenso da sociedade em torno dos valores e interesses da classe dominante.

Esse é o mesmo posicionamento de Demetrius (2013:2), quando afirma que os profissionais de Relações Públicas trabalham para promover os interesses de empresas poderosas, maximizando seus lucros, ampliando suas participações de mercado e suas influências, sendo capazes de abordar canais midiáticos para que adotem suas narrativas acima de outras. Seu objetivo é produzir um ambiente discursivo que promova comentários favoráveis, e mesmo tendenciosos, fomentando seus próprios interesses.

Por outro lado, há o reconhecimento de que as estratégias e as ferramentas de Relações Públicas contribuem para dar forma à sociedade contemporânea (Gonçalves, 2007:6), principalmente se considerarmos o diálogo visto como elemento fundamental da atividade. Para Bowen (2005: 839), por exemplo, essa é a profissão que tem a responsabilidade de promover a compreensão mútua por meio do debate informado e que, por isso mesmo, funciona como "óleo nas rodas da sociedade".

Peruzzo (2004) vislumbra, também, a possibilidade de as Relações Públicas se desdobrarem em uma nova vertente, a popular, alternativa ou comunitária. Assim, mesmo diante de sua posição claramente crítica à área, Peruzzo (2009:182) afirma que aposta na necessidade do avanço das Relações Públicas, sobretudo neste momento em que elas se mostram cada vez mais imprescindíveis no mundo, diante das redes de interdependência criadas e da obrigação de fazer os interesses públicos prevalecerem sobre os interesses do capital privado, já que, ainda que reconheça que estes sejam legítimos, uma vez enraizados e institucionalizados, não podem suplantar os das pessoas, da sociedade brasileira e do planeta Terra.

Nessa perspectiva, é possível dizer que os princípios dialógicos das Relações Públicas defendidos por Gonçalves e Peruzzo, encontram ressonância, também, em autores como James 
Grunig (1984) e Ron Pearson (1989), já que o diálogo torna-se uma característica dos relacionamentos estabelecidos em contextos democráticos.

Pearson (1989:377), formulou, com base em Habermas, dois imperativos morais para o estudo das Relações Públicas. Em primeiro lugar, defende a manutenção de relações comunicacionais com os públicos, como uma obrigação ética inerente à prática organizacional; em segundo, propõe melhorar a qualidade dessas relações, de maneira a que elas ampliem permanentemente sua dialogicidade.

Assim como Pearson, Grunig destaca, também, a importância da comunicação dialógica, quando defende o modelo simétrico de duas mãos, que busca o equilíbrio entre os interesses das organizações e de seus respectivos públicos, promovendo o entendimento (Grunig, Hunt, 1984).

As prescrições morais sobre as práticas profissionais, no entanto, parecem insuficientes para viabilizar que a atividade, como um todo, seja percebida em seu caráter democrático, relacional e inclusivo. Para Seib e Fitzpatrick (2006:7), "muita da desconfiança nos profissionais de Relações Públicas deriva da falta de confiança pública nas instituições que eles representam". [...] não se pode apenas tentar melhorar a própria reputação junto do público e das organizações que representam agindo eticamente ao nível pessoal, mas também, e sobretudo, procurando activamente "melhorar a responsabilidade social das suas organizações clientes" [...] Neste sentido, poder-se questionar se o elevado grau de responsabilidade que é exigido às Relações Públicas terá tradução fácil na prática.

Nesse mesmo sentido, Henriques (2009:130), explica que as atividades de Relações Públicas, sendo todas aquelas capazes de gerar e manter um relacionamento no espaço público entre as organizações e os grupos a que estão de alguma forma ligadas, exige uma compreensão mais refinada sobre o que realmente fundamenta a atividade: a permanente tensão entre os interesses privados e públicos. O autor afirma que, sob essa perspectiva, entram em jogo a aprovação e a legitimação que os grupos podem ou não conferir a uma organização.

Essas considerações iniciais reforçam a necessidade de se aprofundar a análise sobre o compromisso, das Relações Públicas com o interesse público, se localizando acima do interesse particular e organizacional. Para fundamentar essa reflexão, partimos de Habermas como principal referência, aproximando os conceitos de esfera pública democrática e Relações Públicas.

\section{Esfera pública democrática e esfera privada}

Diferentes reflexões sobre a esfera pública e a democracia já foram realizadas no campo comunicacional. A presente análise resgata a contribuição de Habermas (e de outros autores), para buscar compreender as consequências da emergência de múltiplas esferas públicas na sociedade, e suas interfaces com os contextos organizacionais.

Habermas (2003) localiza a esfera pública entre o Estado e o espaço maior da sociedade, ou mundo da vida, onde se formam diversas arenas e fluxos comunicativos em disputa por visibilidade e legitimidade. Esta construção já nos permite apontar que as políticas organizacionais, incluindo as que se referem às Relações Públicas, produzem um impacto inevitável sobre o funcionamento dessa rede de conteúdos e opiniões, chamada esfera pública. Esta importância 
está relacionada à contribuição que estratégias e práticas organizacionais devem oferecer ao debate, e à inclusão de sujeitos, na comunicação pública.

Marques (2008:27) indica que, para garantir que todos participem igualmente dos debates e discursos em contextos formais e informais, é necessário que os atores sigam procedimentos que garantam condições de igual participação e consideração de todos.

A partir disso, pode-se propor que, também no âmbito organizacional, deva existir igualdade de participação e de consideração das diferentes posições, considerando-o como reflexo do espaço público democrático. Nesse processo, a interação entre os atores sociais deve ser mediada pela accountability (processo de submissão de uma posição à análise e validação do outro), pela igualdade, pelo respeito mútuo e pela autonomia política (Marques, 2008:28). Para tanto, a comunicação se torna instrumento fundamental de circulação de informação, entre a periferia do sistema social e o centro tomador de decisões.

Gugliano (2004) critica, por sua vez, a relação positiva que possa haver entre o capitalismo e a democracia. Seu argumento coloca em relevo a deterioração ambiental, cultural e social do planeta, produzida pelo capitalismo em função de sua ênfase na questão econômica. Diante deste cenário, questionam-se as possibilidades reais de se promover a cidadania e os direitos sociais.

O autor sinaliza, então, a perspectiva de análise qualitativa da democracia, utilizada por diferentes estudiosos para acompanhar a trajetória dos novos regimes - da chamada terceira onda da democratização. Como se depreende desta perspectiva, a democracia é aqui defendida, diferentemente da posição de autores que tratam de delimitá-la aos procedimentos de escolhas de líderes e representantes políticos. Esse modelo confina o regime a um campo de dominação social, pois o Estado torna-se o elemento de legitimação dos mecanismos de organização coercitiva, buscando, segundo Tilly (1992:20), a aceitação da validade legal de suas intervenções.

Além disso, nessa perspectiva, a democracia não abrange o mercado e suas instituições econômicas, assim como não se relaciona diretamente com a infraestrutura da sociedade. Essa restrição preserva organizações ligadas à produção, à comercialização e à transação de bens com valor monetário, de aplicarem as prerrogativas democráticas na sua forma de gestão. Diante dessa exclusão, o planejamento estratégico dos objetivos organizacionais ganha licença para priorizar o lucro privado, acima dos interesses de bem-estar da população.

Assim, o mercado econômico separado da gestão democrática acaba promovendo a cisão entre o público e o privado, com ausência de limites na busca da satisfação (econômica) individual. Por isso, são frequentes as atividades econômicas que fogem dos padrões éticos e morais das sociedades contemporâneas.

Todas essas considerações levam à necessidade de se repensar a teoria da democracia, para ampliar o cânone democrático, conforme sugere Santos (2002); inserindo, na vida cotidiana dos cidadãos, aqueles processos anteriormente restritos aos círculos governamentais e parlamentares. Em propostas mais participativas, o processo democrático se estrutura em variados níveis de reuniões, que envolvem moradores de diferentes cidades e regiões. Estimula-se, aí, 
o debate sobre o espaço urbano, as escolhas de obras públicas, ou a indicação de representantes locais nos fóruns de gestão. Ao final, ocorre uma revolução na constituição do capital social(1), à medida que as esferas não-estatais (Santos, 2002) também se democratizam e se vinculam.

Esteves (2003) aborda a constituição histórica do espaço público, e sua dificuldade em se tornar verdadeiramente democrático para a participação da sociedade civil. Destaca, também, a centralidade da comunicação, em especial da mídia de massa, no processo de formatação de um espaço público - hoje fragmentado e diluído.

Ao mesmo tempo, Esteves afirma que o espaço público não teria extinguido toda a sua vitalidade. Em vez disso, o que houve foi uma reconfiguração da sociedade civil ao longo da história, transformando a sociedade burguesa em núcleo estruturado de associações voluntárias, autônomas em relação ao Estado e à economia. Isso faz com que a força regeneradora que a sociedade civil fornece ao espaço público dependa, tanto de sua delimitação em relação ao Estado, quanto da promoção de uma ação social responsável no mercado.

\section{Relações públicas na democracia deliberativa}

O conceito de deliberação que acompanha as discussões sobre a esfera pública oferece, em nossa análise, o elo necessário pra entrelaçar a democracia e as Relações Públicas, de forma mais evidente. A política deliberativa cumpre o papel crucial de fornecer legitimidade às decisões, tomadas no âmbito democrático. Segundo Habermas (1997:28), a validação dessas escolhas depende da qualidade dos argumentos racionais apresentados durante o processo de formação de opiniões e vontades.

Aqui, vale também observar, conforme Castellano (2011:189), que o debate público, fundamental para a democracia, é e deve ser praticado por cidadãos críticos e ativos, os quais não dependem de nenhuma formação específica para atuar, pelo contrário.

A troca argumentativa preenche, então, uma função social e integradora dos sujeitos políticos, reunidos para tomar decisões coletivas e vinculantes em sua comunidade. Por isso, o nível discursivo do debate público constitui a variável mais importante do processo democrático.

Habermas (idem:29) se apoia nos postulados de Cohen para caracterizar o modelo deliberativo ideal, a partir dos seguintes procedimentos ou normas: as deliberações realizam-se de forma argumentativa, portanto, através da troca regulada de informações e argumentos entre as partes, que recolhem e examinam criticamente as propostas em jogo; as deliberações devem ser inclusivas e públicas; pretendem-se livres de coerções externas e internas, que poderiam colocar em risco a situação de igualdade dos participantes.

Castellano (2011:189), ao se referir a Lasch (1995), rerforça que o debate sério ocorre quando há uma clara abertura para que todos os cidadãos participem, e sua seriedade se mede pela intenção de levantar assuntos de interesse público que busquem o bem comum e uma maior democratização.

O agir comunicativo é o responsável por estabelecer relações, estimulando os vínculos sociais. 
O que associa os parceiros do direito é, em última instância, o laço linguístico que mantém a coesão de qualquer comunidade comunicacional. É possível afirmar, portanto, que as Relações Públicas ganham força no contexto democrático idealizado pelos procedimentos deliberativos, uma vez que eles demandam operações que favoreçam a formação de vínculos discursivos.

Como resultado, o processo deliberativo permite a formação de um poder que é produzido comunicativamente, que ocorre em meio ao processo decisório na vida política, mantendo a divisão entre as esferas privadas e as esferas públicas.

Todavia, a esfera pública retira seus impulsos da assimilação privada de problemas sociais, que repercutem na vida de cada indivíduo, ou seja, o privado impacta o público, e vice-versa. Se, por um lado essa relação se revela praticamente como algo inerente a uma sociedade democrática e de ampla informação, de outro, é preciso também reconhecer o direito à privacidade, ainda que avanços tecnológicos (com destaque para a internet e as mídias sociais), tornem cada vez mais híbridas as relações entre as esferas privadas e as esferas públicas, por meio da publicização dos espaços reservados à intimidade.

Diante da percepção sobre a diluição das fronteiras entre o público e o privado, surge, portanto, o desafio de se ampliarem os espaços de participação e de debate, também no âmbito das organizações, para que sejam capazes de promover uma cultura democrática - para além das estruturas oficiais da política. Nesse contexto, a linguagem assume um papel central, já que, conforme Habermas, é o meio de entendimento especificamente humano, que permite substituir, a violência, pelo consenso racional entre cidadãos responsáveis (Burkart, 2007: 249-254).

É nessa perspectiva do entendimento coletivo, que se pode empregar a Teoria da Ação Comunicativa (Habermas,1984,1987) para as Relações Públicas. Ela propõe que a comunicação sempre acontece como um processo multidimensional, em que cada participante precisa aceitar a validade de certas demandas, ou reivindicações quase universais, para alcançar os consensos. Quando as regras básicas de comunicação são violadas, o discurso é o mecanismo fundamental de reparação.

Por meio do discurso, as pessoas exercem a oportunidade de duvidar da verdade das afirmações, da confiabilidade das expressões e da legitimidade dos interesses, durante um processo argumentativo. $O$ discurso é o vetor para a apresentação dos argumentos plausíveis, que, segundo Habermas, permitem a continuidade do fluxo de comunicação (Burkart, 2007). No contexto das organizações, os gestores e profissionais de Relações Públicas assumem papel e responsabilidade relevantes, como portadores de discursos e mensagens a serem questionadas por públicos críticos.

Assim, a partir de questões análogas às Relações Públicas, como a busca de compreensão, entendimento e resolução dialogada de conflitos, é possível extrair, da teoria habermasiana, a essência da atividade. De um lado, essa proposta confirma os valores da formação de relacionamentos baseados em confiança, transparência, ética e responsabilidade. Mas, de outro lado, este ideal se distancia do enclausuramento, das Relações Públicas, no universo específico das organizações. 


\section{Relações públicas e o interesse público}

A instituição democrática existe para legitimar decisões administrativas. No entanto, no âmbito das organizações privadas, há pouco ou nenhum espaço de participação no processo decisório, o que se revela como incoerente no contexto da democracia. Consequentemente, as decisões tomadas pelas organizações privadas são, em geral, puramente técnicas, desconsiderando-se os interesses dos afetados. Habermas (1997) opina que o quadro institucional deve ser racionalizado pela "remoção das restrições comunicativas".

Esse é o questionamento que cerca a presente reflexão, já que, no contexto democrático, deve-se levar em conta os espaços de interlocução que estimulem, nos sujeitos, a cultura de engajamento, deliberação e participação no processo decisório.

O sentido amplo das Relações Públicas está fundamentado na promoção dessa prática democrática, dialogada em todos os momentos e espaços, uma vez que a atividade orienta-se pelo estabelecimento de relacionamentos públicos em torno das mais diferentes questões e interesses. Como esse processo indica potencial de conflito, torna-se essencial a busca de formas de conciliação, com a criação e a utilização de espaços que podem ser vistos como arenas (presenciais e virtuais), onde as trocas argumentativas sejam realizadas e consideradas.

Nessa perspectiva, podemos afirmar que as Relações Públicas só podem efetivamente ocorrer em contextos democráticos, onde a cidadania pode ser exercida. Afinal, conforme Scherer-Warren(1999:60), a ampliação dos direitos de cidadania relaciona-se com os processos de democratização da sociedade. Peruzzo (1999:287) define que

ser cidadão é ter direito de ver-se protegido legalmente, de locomover-se, de interferir na dinâmica política, de votar e ser votado, de expressar-se. É também ter o direito de morar numa casa digna, de comer bem, de poder estudar e trabalhar. É, por fim, ter o direito de participar, com igualdade, na produção, na gestão e na fruição dos bens econômicos e culturais.

Diante da defesa do direito de interferir na dinâmica política, e de participar na gestão de bens econômicos e culturais, Buhmann (2011) preocupa-se com os efeitos para a sociedade como um todo, das decisões das organizações competitivas. O autor considera que o material e a estrutura discursiva do ambiente de trabalho precisam ser compreendidos, de modo a propor resoluções ou supressões dos conflitos corporativos. Ele examina o desenvolvimento histórico da corporação moderna, mostrando a emergência dos diferentes papéis, o processo de formação de consciência entre seus atores, e o desenvolvimento dos interesses gerenciais.

Podemos apreender, a partir desta análise, que o alinhamento entre as políticas de Relações Públicas e o interesse público depende dos valores com os quais a organização se compromete - e que, portanto, estão incorporados em sua cultura organizacional. Como propõe Buhmann (2011), é necessário analisar, então, o nível de consciência que as empresas são capazes de ter sobre as questões de interesse público.

Para tanto, é útil recuperar, aqui, o modelo dos Sete Níveis de Consciência desenvolvido por Richard Barrett e citado por Fejgelman ( 2008: 154-156), que permite identificar as diferenças de comprometimento organizacional. 


\section{Níveis de consciência pessoal e organizacional}

\begin{tabular}{|c|c|c|}
\hline Níveis & Níveis de Consciência Pessoal & Níveis de Consciência Organizacional \\
\hline 1 & $\begin{array}{l}\text { Sobrevivência - Focaliza as questões de } \\
\text { sobrevivência física. Inclui valores como } \\
\text { estabilidade financeira, riqueza, segurança, } \\
\text { autodisciplina e saúde. Os aspectos poten- } \\
\text { cialmente limitadores deste nível são gera- } \\
\text { dos por medos em torno da sobrevivência. } \\
\text { Valores limitantes incluem ganância, contro- } \\
\text { le e cautela. }\end{array}$ & $\begin{array}{l}\text { Finanças - Focaliza a questão financeira e } \\
\text { o crescimento organizacional. Inclui valores } \\
\text { como lucratividade, valor do acionista, saúde } \\
\text { e segurança do funcionário. Os valores poten- } \\
\text { cialmente limitantes deste nível são gerados } \\
\text { pelo medo da sobrevivência, como controle, } \\
\text { territorialidade, cautela e exploração. }\end{array}$ \\
\hline 2 & $\begin{array}{l}\text { Relacionamentos - Preocupa-se com a } \\
\text { qualidade dos relacionamentos interpes- } \\
\text { soais. Inclui valores como comunicação, fa- } \\
\text { mília, amizade, resolução de conflitos e res- } \\
\text { peito. Os aspectos potencialmente limitantes } \\
\text { deste nível resultam de medos em relação à } \\
\text { perda de controle ou consideração. Valores } \\
\text { limitantes incluem rivalidade, intolerância e } \\
\text { necessidade de ser gostado. }\end{array}$ & $\begin{array}{l}\text { Relacionamentos - Contempla a qualidade } \\
\text { dos relacionamentos interpessoais entre co- } \\
\text { laboradores e clientes/fornecedores e inclui } \\
\text { valores como comunicação aberta, resolução } \\
\text { de conflitos, satisfação do cliente, cortesia e } \\
\text { respeito. Os aspectos potencialmente limi- } \\
\text { tantes deste nível nascem de medos relacio- } \\
\text { nados à perda de controle e consideração } \\
\text { pessoal. Isso gera manipulação, culpabiliza- } \\
\text { ção e competição interna. }\end{array}$ \\
\hline 3 & $\begin{array}{l}\text { Autoestima - Enfatiza a questão do reco- } \\
\text { nhecimento. Ele inclui valores como ser o } \\
\text { melhor, ambição, crescimento profissional } \\
\text { e recompensa. Os aspectos potencialmente } \\
\text { limitantes deste nível se originam de uma } \\
\text { baixa autoestima ou da perda de controle. } \\
\text { Valores potencialmente limitantes incluem } \\
\text { status, arrogância e imagem. }\end{array}$ & $\begin{array}{l}\text { Autoestima - Preocupa-se com práticas de } \\
\text { gestão que melhoram os métodos de trabalho } \\
\text { e a entrega de serviços e produtos, incluin- } \\
\text { do valores como produtividade, eficiência, } \\
\text { crescimento profissional, desenvolvimento de } \\
\text { habilidades e qualidade. Os aspectos poten- } \\
\text { cialmente limitantes são o resultado de baixa } \\
\text { autoestima e da perda de controle e incluem } \\
\text { valores como status, arrogância, burocracia e } \\
\text { complacência. }\end{array}$ \\
\hline 4 & $\begin{array}{l}\text { Transformação - Focaliza a autorrealiza- } \\
\text { ção e crescimento pessoal. Contém valores } \\
\text { como coragem, responsabilidade e desen- } \\
\text { volvimento pessoal. Este é o nível em que as } \\
\text { pessoas trabalham para se libertar de seus } \\
\text { medos. Isso requer um questionamento con- } \\
\text { tínuo das próprias crenças e pressupostos. É } \\
\text { também o nível em que o profissional encon- } \\
\text { tra equilíbrio em sua vida. }\end{array}$ & $\begin{array}{l}\text { Transformação - Visa à renovação contínua } \\
\text { e ao desenvolvimento de novos produtos e } \\
\text { serviços. Ele contém valores que sobrepõem } \\
\text { os valores potencialmente limitantes dos } \\
\text { níveis } 1 \text { a 3. Valores neste nível incluem res- } \\
\text { ponsabilidade, participação do funcionário, } \\
\text { aprendizagem, inovação, trabalho em equipe, } \\
\text { desenvolvimento pessoal e compartilhar co- } \\
\text { nhecimento. }\end{array}$ \\
\hline 5 & $\begin{array}{l}\text { Significado - Voltado para a preocupação } \\
\text { do indivíduo com a busca de significado e } \\
\text { comunidade. Aqueles que operam como } \\
\text { neste nível não pensam mais em termos de } \\
\text { emprego ou cargo, mas em termos de mis- } \\
\text { são. Esse nível contém valores como com- } \\
\text { prometimento, criatividade, entusiasmo, } \\
\text { humor/alegria, excelência, generosidade e } \\
\text { honestidade. }\end{array}$ & $\begin{array}{l}\text { Coesão Interna - Foca o espírito de comuni- } \\
\text { dade na empresa. Ele inclui valores confian- } \\
\text { ça, integridade, honestidade, consciência de } \\
\text { valores, cooperação, excelência e justiça. O } \\
\text { resultado é alegria, entusiasmo, paixão, com- } \\
\text { prometimento e criatividade. }\end{array}$ \\
\hline
\end{tabular}




\begin{tabular}{|c|c|c|}
\hline 6 & $\begin{array}{l}\text { Fazer a diferença - Envolve o interesse de } \\
\text { fazer a diferença no mundo. É também o ní- } \\
\text { vel de envolvimento ativo na comunidade lo- } \\
\text { cal. Indivíduos operando neste nível honram } \\
\text { a instituição e a contribuição. Eles podem } \\
\text { estar preocupados com o meio ambiente ou } \\
\text { questões locais. Contém valores como acon- } \\
\text { selhamento, trabalho comunitário, empatia e } \\
\text { consciência ambiental. }\end{array}$ & $\begin{array}{l}\text { Inclusão - Foca no amadurecimento e for- } \\
\text { talecimento dos relacionamentos e na reali- } \\
\text { zação do funcionário. Dentro da organização } \\
\text { inclui valores como desenvolvimento da lide- } \\
\text { rança, capacidade de ser mentor e realização } \\
\text { do funcionário. Externamente inclui valores } \\
\text { como colaboração com clientes e fornecedo- } \\
\text { res, criar parcerias, alianças estratégicas, en- } \\
\text { volvimento com a comunidade, consciência } \\
\text { ambiental e fazer a diferença. }\end{array}$ \\
\hline 7 & $\begin{array}{l}\text { Servir - Reflete a mais alta ordem de co- } \\
\text { nexão interna e externa. Foca no servir aos } \\
\text { outros e ao planeta. Indivíduos operando } \\
\text { neste nível lidam bem com a incerteza. Eles } \\
\text { demonstram sabedoria, compaixão e ca- } \\
\text { pacidade de perdoar, têm uma perspectiva } \\
\text { global e estão preocupados com questões } \\
\text { como justiça social, direitos humanos e fu- } \\
\text { turas gerações. }\end{array}$ & $\begin{array}{l}\text { Unidade - Reflete o nível mais alto de cone- } \\
\text { xão interna e externa. Dentro da organização } \\
\text { inclui valores como visão, sabedoria, capaci- } \\
\text { dade de perdoar e compaixão. Externamente } \\
\text { incluir valores como justiça social, direitos hu- } \\
\text { manos, perspectiva global e futuras gerações. }\end{array}$ \\
\hline
\end{tabular}

Conforme pode ser observado, a evolução do nível de consciência, seja pessoal ou organizacional, depende da cultura, dos valores e da maturidade. Isso sugere que as empresas efetivamente comprometidas com o interesse público são aquelas que estão localizadas em níveis mais elevados de consciência, já que os patamares mais baixos restringem-se a buscar a sobrevivência pessoal, ou a atender à sustentabilidade financeira das organizações.

Tal abordagem nos leva a entender por que há empresas que têm avançado na interação entre público e privado, enquanto outras se mostram distantes dessa percepção. Todavia, como a sociedade cobra das empresas seu compromisso com o interesse público, aquelas que se encontram em níveis mais "inferiores de consciência" tendem a esconder as reais intenções de suas ações sociais ou ambientais (quando as realizam), camuflando interesses basicamente promocionais.

Diante da diluição das fronteiras entre o público e o privado no contexto democrático, participação, diálogo e engajamento devem fundamentar as políticas de comunicação e de Relações Públicas. Esse panorama fortalece o exercício da cidadania, e coloca as empresas diante do desafio de atuarem em prol do interesse público, exigindo preparação adequada para lidar com as manifestações (positivas ou negativas), que venham a enfrentar. Não é sem motivo que as organizações precisam incluir, em suas políticas sociais e ambientais, as estratégias de comunicação e de relacionamento capazes de promover o engajamento, a participação e a deliberação, contribuindo para a construção de um capital social positivo.

Essas políticas devem, por sua vez, extrapolar o próprio contexto organizacional, ampliando sua atuação e seus objetivos para o âmbito público. Evidentemente, essa conduta exige que as práticas de comunicação e de relacionamento não se limitem apenas à promover informação. 


\section{Relações públicas e a constituição de capital social}

Neste ponto, abordamos o conceito de capital social para ampliarmos a análise das relações entre o público e o privado, em direção ao estabelecimento de vínculos entre membros que compõem as organizações. São esses laços que contribuem para garantir o engajamento, seja em relação aos objetivos intraorganizacionais, seja em relação aos objetivos voltados ao interesse público.

Reis (2003), analisando a obra de Putnam, considera o capital social como a variável-chave para identificar as potencialidades de implementação (bem-sucedida) de políticas e de programas públicos em contextos variados. Ele está intimamente ligado às redes sociais e de comunicação disponíveis para as interações dos agentes sociais (Matos, 2009:101).

Matos (2007:55) destaca, também, que "a rede social pode ser dimensionada pela confiança que os membros atribuem aos participantes e às consequências associadas a esse sentimento". E cita Coleman, para quem o capital social pode ser encontrado em dois tipos de estrutura: nas redes sociais que funcionam num espaço fechado (como um clube, com suas próprias normas e sanções), ou numa organização com objetivo específico (empresa, governo, associação cultural, partido político, ONG). Neste último caso, a organização ou instituição pode ampliar seu objetivo primário (lucro, gestão, eleição), para integrar uma ação ou causa social. É exatamente a partir dessas definições que podemos conectar a discussão sobre o capital social com a ampliação das fronteiras organizacionais no contexto democrático.

Coleman (no campo da educação) e Putnam (com foco na participação cívica e no comportamento das instituições) são fontes de inspiração para a maior parte dos estudos sobre o capital social. As pesquisas na área concentram-se, segundo Matos (2009:38), em nove campos: família; comportamento juvenil, escolarização e educação; vida comunitária virtual e cívica; trabalho e organização; democracia e qualidade do governo; ação coletiva; saúde pública e meio ambiente; delinquência e violência; desenvolvimento econômico.

Considerando essas áreas de estudo, é possível perceber que as pesquisas sobre capital social já têm enfatizado o universo organizacional, incluindo as empresas privadas. Reis (2003:44), por exemplo, baseia-se em Putnam (1997:177) para reforçar que o capital social é visto como um facilitador da cooperação voluntária, e é decisivo para a instauração dos círculos virtuosos que favorecem o bom desempenho institucional. Porém, o autor recorre às análises de Dietlind Stolle e Thomas Rochon, para quem as organizações orientadas para o lucro são menos propensas a alimentar laços comunitários de reciprocidade, quando comparadas com as associações com fins sociais.

Fica claro que diversas abordagens têm sido utilizadas nos estudos desse campo. Para Vale et al (2006:46), no entanto, ainda há escassez de análises sobre o papel do capital social nos estudos organizacionais. Por isso, apresentam uma contribuição importante, ao demonstrar que o ambiente organizacional constitui-se num espaço rico e interessante para seu estudo. Eles chamam a atenção para a necessidade de análises sobre as relações externas, incluindo outras organizações, como as do setor público e do terceiro setor.

A transição, das estruturas verticais e hierarquizadas para modelos horizontais e flexíveis, tam- 
bém pressiona as organizações para uma atuação menos delimitada em seus próprios contornos. Isso provoca a necessidade de se estabelecer estratégias coletivas, voltadas a promover relações de confiança mútua, senso de propósito e capacidade de trabalho coletivo - elementos subjacentes ao conceito de capital social, assim como ao de Relações Públicas.

Nesse contexto de transformação das dinâmicas gerenciais e na globalização das atividades organizacionais, esses autores chamam a atenção para a força das novas tecnologias de informação e comunicação. Ao mesmo tempo em que a organização se expande em suas relações externas, a qualidade do ambiente interno também provoca preocupações, diante de estruturas mais enxutas, descentralizadas e participativas. Reforça-se, mais uma vez, o papel das Relações Públicas no impulso à interação e à colaboração.

Vale et al (2006: 59) trazem outra contribuição, ao indicarem formas de mensurar o capital social nas redes organizacionais, utilizando dois eixos: um vertical, baseado na intensidade dos vínculos (bonding) da organização, no interior de certos segmentos; e um horizontal, que capta as pontes (bridging) que a empresa é capaz de estabelecer com grupos mais distantes. [...] um incremento do capital social [ocorreria] à medida em que as empresas intensificassem seus contatos e interações dentro de suas próprias comunidades de origem - permitindo a proliferação da inovação baseada no conhecimento tácito, de natureza presencial, entre as empresas aí presentes, a criação de um clima de maior solidariedade local e a capacidade de implementação de ações coletivas. Mas ocorreria, também, um incremento no capital social, à medida que a empresa ampliasse o escopo, a amplitude e a variedade de suas relações, tornando possível o acesso a recursos distantes, diversificados e valiosos porventura existentes em outras redes e locais, e a geração de um fluxo de informação entre eles. (Vale et al, 2006:59)

Essas considerações são mais do que válidas, dentro de uma temática que se propõe a evidenciar uma nova perspectiva para as Relações Públicas, diante da diluição das fronteiras entre a esfera organizacional e as esferas públicas. O capital social, afinal, está na essência das relações que criam vínculos entre os membros, sendo capazes de comprometê-los com as questões organizacionais e de interesse público.

\section{Conclusão}

A presente análise procurou refletir sobre a atual práxis das Relações Públicas, questionando que, mesmo dentro do contexto democrático, a área ainda se baseia em modelos que privilegiam o interesse privado, em detrimento do interesse público. Além disso, aqueles para quem suas ações são destinadas (denominados como públicos), continuam a ser considerados objetos ou alvos, faltando perceber que os indivíduos têm se tornado cidadãos, que precisam ser transformados em sujeitos das políticas públicas e organizacionais, participando diretamente de suas definições.

Ao sugerir caminhos para a ação social e política das Relações Públicas, este artigo defendeu que essas devem ter o compromisso com o interesse público. Inclui-se, aí, o papel dos diferentes atores, como é o caso das organizações privadas, que precisam estar alinhadas com o contexto democrático, ajustando seus modelos e fortalecendo suas políticas de comunicação e de relacionamento. 
Tais políticas também devem identificar e reconhecer o capital social existente, além de contribuir com sua constituição, facilitando o engajamento dos cidadãos nos assuntos que afetam a coletividade, por meio da promoção de vínculos de confiança entre organizações e seus diversos públicos.

Afinal, se os recursos comunicativos têm ampliado as possibilidades de participação do sujeito, seja no âmbito público ou organizacional, pode-se, então, vislumbrar um papel ampliado para as Relações Públicas. Nesse contexto, é necessário, mais do que definir ferramentas e técnicas de comunicação, promover alternativas de interlocução e de estímulo à participação - com vistas ao fortalecimento de vínculos sociais, a partir do ambiente interno, até alcançar o ambiente externo.

Isso implica uma nova relação a ser estabelecida a partir das organizações, com incremento do capital social, que faz proliferar a cooperação, ao invés de competição, e um clima de maior solidariedade se institui, sendo, gradativamente, refletido nas esferas públicas.

Esse movimento, do interno para o externo, do organizacional para o público, vem provocando uma mudança nas práticas de relacionamento e de comunicação, que já não concebem ações realizadas para os indivíduos e grupos, sem que estes participem, opinem, reivindiquem, e questionem.

O sentido amplo das Relações Públicas está, pois, fundamentado na prática democrática, dialogada em diversos contextos, incluindo as organizações privadas, já que os efeitos de suas decisões trazem impacto para a sociedade como um todo.

Tais reflexões dirigem-se à análise do impacto das Relações Públicas na sociedade, seu alinhamento com valores democráticos, e o futuro previsto para a atividade, principalmente por entendermos que essas não se fazem para, e sim, com os públicos, pois devem ser construídas coletivamente.

Se as Relações Públicas, ainda hoje, são questionadas por servirem aos interesses privados, por conceberem suas estratégias direcionadas para públicos, como se fossem constituídos por indivíduos amorfos, é chegado o momento de se colocar em prática a essência da área. Demostra-se, dessa forma, sua função social voltada para construir relacionamentos de confiança, compartilhamento e engajamento, por meio de diálogo, de respeito, de participação, fazendo-se jus ao contexto democrático.

Além disso, o mundo interconectado por redes de interdependência, contribui para que se constitua o cenário propício para o avanço da área, que vai além de sua atuação organizacional.

É preciso reconhecer, porém, que mesmo no âmbito organizacional, há, também, um papel imprescindível a ser desempenhado pelas Relações Públicas, ao promover nas organizações uma cultura democrática que possibilite a igualdade de participação e de consideração das diferentes posições. 
Nessa perspectiva, Relações Públicas passa a ser instrumento de consolidação de uma cultura democrática que alcança os indivíduos em esferas privadas e públicas, contribuindo para a formação do cidadão, respeitado e entendido como tal, o que permite emergir um novo sujeito político, capaz de contribuir para opinar e interferir na definição dos caminhos a serem percorridos por nossa sociedade.

\section{Referências bibliográficas}

- $\quad$ BOWEN, S. A. Ethics of Public Relations. In: Robert L. Heath (org.). Encyclopaedia of Public Relations. Sage, NY, 2005.

- $\quad$ BUHMANN, Alexander. Applying Habermas' Theory to Public Relations: Potentials and Challenges. Disponível em dokumentix.ub siegen.de/opus/volltexte/2011/517/pdf/buhmann.pdf. Cap 8 - O surgimento da forma moderna de comunicação.

- $\quad$ BURKART, R. Public Relations Review. Jürgen Habermas e Relações Públicas. Departamento de Comunicação, Universidade de Viena, Áustria, 2007. 249-254.

- CASTELLANO, Clara. Webjornalismo participativo e o resgate do debate público. In: MARQUES, Ângela; MATOS, Heloiza (orgs.). São Paulo, Summus, 2011.

- $\quad$ CRAIG, R. T; MULLER, H. L. Theorizing Communication Reading Across Traditions, Sage Publicartions, Inc., 2007.

- DEMETRIOUS, Kristin. Public relations, activism, and social change speaking up. New York, US, Oxfordshire, UK: Routledge, 2013.

- $\quad$ ESTEVES , João Pissarra. "Espaço Público político" (cap. 1) em Espaço público e democracia: comunicação, processo de sentido e identidade social. São Leopoldo, Unisinos, 2003.

- FEIGELMAN, D. B. Valores compartilhados: o desafio de levar a teoria à prática. In: Organicom - Revista Brasileira de Comunicação Organizacional e Relações Públicas. Ano 5, número $8,1^{\circ}$.semestre 2008.

- $\quad$ GIL, A. C. Métodos e técnicas de pesquisa social. São Paulo: Atlas, 1994.

- GONÇALVES, G. M. P. Ética das Relações Públicas. A falta de responsabilidade social nos Códigos Éticos de Relações Públicas. Artigo apresentado no IX Congresso International Association for Media and Communication Research (IAMCR), no Grupo de Trabalho "Ethics of society. Ethics of Communication" em Paris, 24/07 de 2007.

- GRUNIG, J. E., HUNT, T. Managing Public Relations. New York, Holt, Rinehart \& Winton, 1984.

- GUGLIANO, Alfredo Alejandro. Democracia, participação e deliberação: Contribuições ao debate sobre possíveis transformações na esfera democrática. Porto Alegre, Civitas, no. 2, Jul-Dez, 2004.

- HABERMAS, J. The theory of communicative action. Vol 1. Reason and the rationalizalion of society. Boston, Beacon Press, 1984.

- HABERMAS, J. The theory of communicative action. Vol 2. Lifeworld and sistem: A critique of functionalist reason. Boston, Beacon Press, 1987.

$\cdot$ Direito e Democracia.: entre facticidade e validade. Rio de Janeiro, Tempo Brasileiro, vol.II, 1997.

- O papel da sociedade civil e da esfera pública política (VIII) em: Direito e Democracia entre facticidade e validade . livro II , Tempo brasileiro, Rio de Janeiro, 2003.

- HENRIQUES, Márcio Simeone. Relações Públicas: O futuro da atividade é o futuro da profissão? Revista Organicom. Ano 6, Edição Especial, números 10/11. Disponível em (file:/// Users/mariajosedacostaoliveira/Documents/128.pdf) 
- $\quad$ MARQUES, Angela C. S. "Os meios de comunicação na esfera pública: novas perspectivas para as articulações entre diferentes arenas e atores. Em Revista Líbero, Ano XI n. 21, junho de 2008.

- MATOS, H. Capital Social e Comunicação: interfaces e articulações, São Paulo: Summus editorial, 2009.

- _ Comunicação pública, esfera pública e capital social. In: DUARTE, J. (org) Comunicação Pública. Estado, mercado, sociedade e interesse público. São Paulo, Atlas, 2007, 2aEd.

- PEARSON, Ron. Beyond ethical relativism in public relations: co-orientation, rules, and the idea of communication symmetry. In: J. E. Grunig; L. A. Grunig (Eds.). Public Relation Research Annual (Vol. 1, pp. 67-86), Hillsdale, NJ, Lawrence Erlbaum, 1989.

- PERUZZO, Cicilia. M. K. Relações Públicas no Modo de Produção Capitalista. $2^{a}$. ed. São Paulo, Summus, 1986.

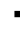

.Relações Públicas com a Comunidade: Uma agenda para o Século XXI. Artigo apresentado no GT de Relações Públicas do XXII Congresso Brasileiro de Ciências da Comunicação. Intercom, Rio de Janeiro, 1999.

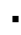
Comunicação nos movimentos populares: a participação na construção da cidadania. 3ª. Ed. São Paulo, Vozes, 2004.

- — Da aparência à essência das Relações Públicas: abordagem na perspectiva da teoria crítica e do modo de produção capitalista.(157-184).In: KUNSCH, M. K. K. (Org.). Relações públicas: história, teorias eestratégias nas organizações contemporâneas. São Paulo, Saraiva, 2009.

- PUTNAM, R. D. Comunidade e Democracia: a experiência da Itália moderna. Rio de Janeiro, Fundação Getúlio Vargas, 1997.

- REIS, B. P. W. Capital Social e Confiança: Questões de teoria e método. Revista Sociologia Política, 21, p. 35-49, nov. 2003.

- RÜDIGER, Francisco. Relações públicas e pesquisa crítica em comunicação. In: MOURA, Cláudia Peixoto de; FOSSATTI, Nelson Costa (orgs.). Práticas acadêmicas em relações públicas: processos, pesquisas e aplicações. Porto Alegre: Sulina, 2011. p. 42-74.

- SANTOS, Boaventura de Souza e AVRITZER, Leonardo. Para ampliar o cânone democrático. In: SANTOS, B. S. (Org.). Democratizar a Democracia. Rio de Janeiro, Civilização Brasileira, 2002

- $\quad$ SEIB e FITZPATRICK. Public Relations Ethics, Thomson, Belmont, SA, 2006.

- SHERER-WARREN, J. Cidadania sem fronteiras: ações coletivas na era da globalização. São Paulo, Hucitec, 1999.

- $\quad$ TILLY, Charles. Coerción, capital y los Estados europeos. Madri, Alianza, 1992.

- VALE, G. M. V.; AMÂNCIO, R.; LAURIA, M. C. P. Capital Social e suas implicações para o estudo das organizações. O\&S, v. 13, no. 36, Janeiro/Março, 2006.

\section{NOTAS}

(1) Há uma abordagem dedicada ao capital social no final do artigo. 


\section{CURRICULUM VITAE}

Dra. Heloiza MATOS E NOBRE

Docente e Pesquisadora Senior do Programade pós graduação da Escola de Comunicação e Artes da Universidade de São Paulo. Coordenadora do grupo de Pesquisa em Comunicação Pública e Política- COMPOL. Tem ministrado disciplinas de Comunicação Pública e Comunicação Política, e orientado investigações de Mestrado, Doutorado e Pós-doutorado para Jornalistas, Relações Públicas e Publicitários. Possui publicações no Brasil e internacionais.

\section{Dra Maria José da COSTA OLIVEIRA}

Pós-doutora pelo PPGCom/Escola de Comunicações e Artes da Universidade de São Paulo. Atuou como docente e coordenadora de cursos de comunicação em instituições de ensino superior. Presidiu a ABRAPCORP - Associação Brasileira de Pesquisadores da Comunicação Organizacional e Relações Públicas na gestão 2016-2018. É membro e vice-coordenadora do Compol - Grupo de Pesquisa em Comunicação Pública e Política.É autora de livros e artigos. 